\title{
Modeling Analysis of DC Magnetic Bias of Iron Core Reactor of APF
}

\author{
Zujun Ding, ${ }^{1}$ Lutao Liu, ${ }^{2}$ and Baolian Liu' \\ ${ }^{1}$ Department of Electronic and Electrical Engineering, Huaiyin Institute of Technology, Huaian 223001, China \\ ${ }^{2}$ College of Information and Telecommunication, Harbin Engineering University, Harbin 150001, China
}

Correspondence should be addressed to Lutao Liu; liulutao@msn.com

Received 13 September 2013; Revised 21 October 2013; Accepted 30 October 2013

Academic Editor: Zhiguang Feng

Copyright (C) 2013 Zujun Ding et al. This is an open access article distributed under the Creative Commons Attribution License, which permits unrestricted use, distribution, and reproduction in any medium, provided the original work is properly cited.

As one of the main power devices of active power filter (APF), iron core reactor DC magnetic bias would affect the performance of APF. Based on the study of DC magnetic bias mechanism of APF iron core reactor, the data model was established in this paper. The performance of APF device impacted by iron core reactor DC magnetic bias was analysed through the simulation in different DC current conditions, and optimization scheme was proposed to reduce DC magnetic bias to improve working performance of APF. To reduce DC magnetic bias, main circuit parameters and control characteristics were uniform, and reluctance of iron core was increased. Results of the simulations and experiments validated that the improved method could restrain reactor DC magnetic bias to reduce even harmonic current in APF output current, which could greatly optimize APF performance.

\section{Introduction}

Nowadays, with the increase of power electronic devices application, the voltage and current of electric power system have been distorted and it caused serious pollution problems of power supply quality $[1,2]$. Power system harmonics suppression, to improve power quality, has become an urgent problem to be resolved $[3,4]$. Active power filter (APF) is a kind of power electronic devices that is currently used to suppress harmonic and compensate reactive power $[5,6]$. Figure 1 shows a parallel APF structure diagram. Because of the nonlinear load, load current $I_{l}$ has harmonic component, with harmonic suppression current $I_{c}$ of APF. Harmonic component of the system current $I_{s}$ would be reduced. It is clearly seen that APF consists of two parts, including current detection and control units and four-leg inverter main circuit. Through current detection, APF obtains harmonic and reactive current reference value, and through pulse width modulation (PWM) control and drive circuit, inverter main circuit would generate the compensation current to realize harmonic suppression and reactive power compensation function $[7,8]$. As the main power components, the filter reactor $\mathrm{L}$ is connected to power system with converter, and working current of APF device is undertaken. Therefore, the reactor feature is very important to decide the performance of APF [9]. APF filter reactance according to the magnetic medium can be divided into two categories $[10,11]$, which are air core reactor and iron core reactor. Due to the advantages of simple structure and low price, air core reactors were widely applied in the traditional APF, but insulation aging and magnetic leakage problem are the two largest unavoidable defects. So, iron core reactors have got more application in APF instead of air core reactor. DC magnetic bias of converter transformer was researched in documents $[12,13]$, but the study of iron core reactor DC magnetic bias mechanism in APF as high frequency converter is not sufficient [14]. In the actual application process, magnetic bias DC excitation of iron core can lead working current of APF to have large even harmonic current [15] and cause the core saturation. Thereby, it would increase the loss of reactor and reduce the efficiency of APF, which seriously affected the performance of the APF [16]. In this paper, based on study of DC magnetic bias mechanism of iron core reactor of APF, data model was established. The performance of the APF device impacted by the DC magnetic bias was analysed through simulation, and optimization scheme was proposed. Experimental results showed that the optimization could greatly reduce the DC 


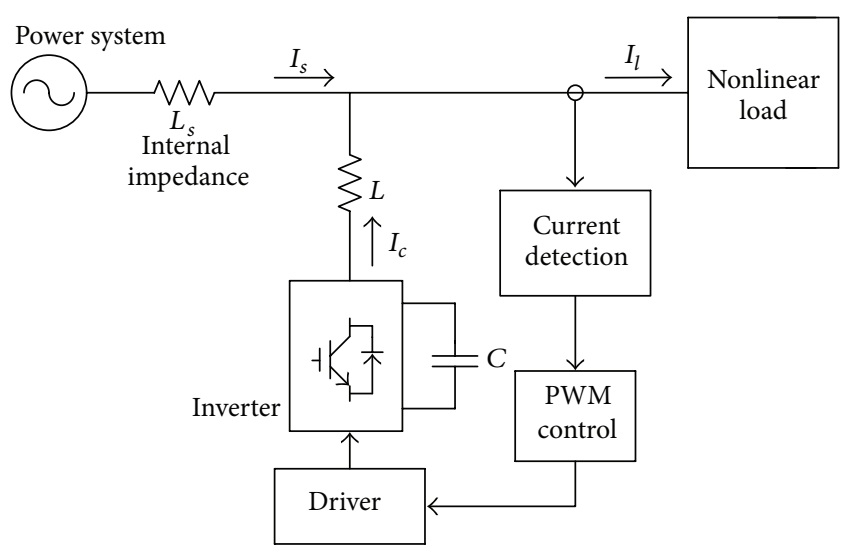

FIgURE 1: APF structure diagram.

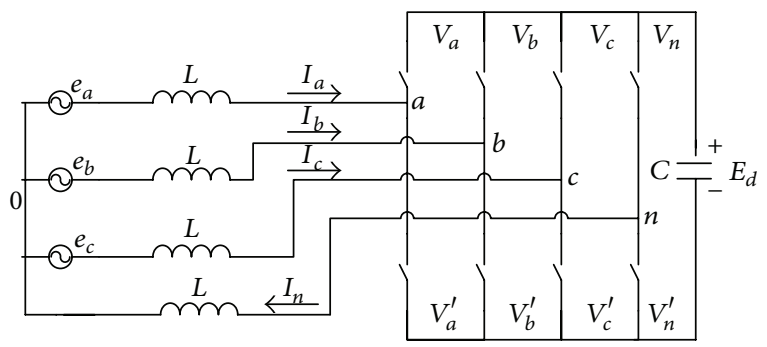

FIGURE 2: Main circuit configuration diagram of APF.

bias magnetic content of core reactor, even harmonic output was reduced to below $1 \%$, and the performance of APF would be greatly optimized. Data-driven fault diagnosis methods become hot topic in industry sectors. So a combination of the proposed method and data-driven techniques is the future work to realize DC magnetic bias compression for APF operation [17-20].

The paper is organized as follows. In the next section, we introduce DC magnetic bias Mechanism of iron core reactor in APF. DC magnetic bias modeling process is extended in Section 3. In Section 4, we give simulation analysis of APF DC magnetic bias. Improved method and experiment of APF are supplied in Section 5 before summarising in Section 6 .

\section{Research on DC Magnetic Bias Mechanism of Iron Core Reactor in APF}

Because the imbalance of forward and reverse volt second area of the transformer or reactor was inevitable in positive and negative pulse process, work hysteresis loop center of the magnetic core deviated from the coordinate origin, and this asymmetrical magnetic working state caused DC magnetic bias. In ideal conditions magnetization process of APF device iron core reactor should be two-way, excitation current should be pure alternating current (AC), and each cycle of iron core magnetic would reset in each repetition period. But because of the actual operation factors of APF, magnetic bias DC excitation of iron core would have DC component, which lead to DC magnetic bias. Specific factors of generating DC magnetic bias are as follows.

(1) The given reference sine wave and triangular wave signal of control system have DC component.

(2) The power electronics devices (IGBT) characteristics and the driving signal transmission delay are different.

(3) The feedback control systems had zero drift.

(4) The application of amplitude limiting in detection and current protection method would cause the imbalance of excitation current.

(5) The magnetic circuit of iron core reactor of APF was asymmetric.

\section{DC Magnetic Bias Modeling of APF}

The main circuit configuration diagram of APF was shown in Figure 2. In this figure, three-phase power system could be expressed as $e_{a}, e_{b}$, and $e_{c}$ and zero line could be expressed as $o$. The filter reactor $\mathrm{L}$ could be expressed as $\mathrm{L}$, and the output currents of APF could be expressed as $I_{a}, I_{b}, I_{c}$, and $I_{n}$. The three-phase four-leg inverter of APF was composed of IGBT devices $\left(V_{a}, V_{a}^{\prime}, \ldots, V_{n}, V_{n}^{\prime}\right)$ and DC capacitor $(C)$. DC-bus voltage of capacitor could be expressed as $E_{d}$. As research object, DC magnetic bias of three-phase four wire APF was modeled, the mathematical expression was established, and the output performance of the DC bias condition of APF device was analysed as follows. The output voltage of APF converter could be expressed as

$$
\begin{aligned}
U_{a n}= & U_{d}+m E_{d} \sin \left(\omega_{0} t+\varphi\right) \\
& +\sum_{n=1}^{\infty} \frac{4}{n \pi}\left\{\frac{n \pi}{2}\left[m \sin \left(\omega_{0} t+\varphi\right)-1\right]\right\} \cos n \omega_{s} t,
\end{aligned}
$$

where $U_{d}$ was DC component of output voltage, $m$ was modulation ration, $E_{d}$ was DC-bus voltage, $\omega_{0}$ was fundamental frequency, and $\omega_{s}$ was carrier wave frequency. Assume resistance of core reactor was $r$; the DC current of reactor coil could be as follows:

$$
I_{d}=\frac{U_{d}}{r}
$$

DC current would generate DC bias magnetic flux $\left(\psi_{d}\right)$ and magnetic induction $\left(B_{d}\right)$, which could be given as

$$
\begin{gathered}
\psi_{d}=\mu H_{d} S=\frac{\mu S N_{i}}{l_{i}} \cdot I_{d}, \\
B_{d}=\frac{\psi_{d}}{S},
\end{gathered}
$$

where $N_{i}$ and $l_{i}$ were the number of windings and magnetic path length of the reactor, $\mu$ was magnetic permittivity of iron core, and $S$ was cross-sectional areas of iron core. According to (1), the following equation could be obtained:

$$
N_{1} \frac{d \psi_{1}}{d t}=m E_{d} \sin \left(\omega_{0} t+\varphi\right)
$$


where $\psi_{1}$ was fundamental magnetic flux. Both sides of (4) were integrated with time $t$; then

$$
\psi_{1}=\frac{m E_{d}}{N_{1} \omega_{0}} \sin \left(\omega_{0} t+\phi-\frac{\pi}{2}\right) .
$$

So, variation amplitude of fundamental magnetic flux $\left(\Delta \psi_{1}\right)$ and induction $\left(\Delta B_{1}\right)$ can be given by

$$
\begin{gathered}
\Delta \psi_{1}=\frac{m E_{d}}{N_{1} \omega_{0}}, \\
\Delta B_{1}=\frac{\Delta \psi_{1}}{S} .
\end{gathered}
$$

In order to improve the utilization ratio of iron core, the maximum magnetic induction intensity would be set near the saturated magnetic induction intensity $\left(B_{s}\right)$. Normally, variation range of flux was between $-\Delta \psi_{1}$ and $+\Delta \psi_{1}$, and variation range of magnetic induction intensity was between $-\Delta B_{1}$ and $+\Delta B_{1}$. Because DC magnetic bias induction intensity existed, magnetic induction intensity ranges between $B_{d}-\Delta B_{1}$ and $B_{d}+\Delta B_{1}$. It led the core work saturation magnetization area and the current to be distorted, which was shown in Figure 3. In this figure, the dotted line was the ideal magnetic excitation process, in which the magnetic induction intensity was sine wave and it was in linearity area of the magnetization curve. So the output current was sine wave, too. However, existence of the DC magnetic bias induction intensity made the magnetic excitation process move to the saturated range of the magnetization curve. The negative and positive half wave curve of the magnetic induction intensity was asymmetric, which was shown as the solid line in Figure 3. The output current of APF was severely distorted. From Figure 3, it can be clearly seen that, with DC magnetic bias, APF working current had large even harmonic current, and it caused output current of APF halfwave asymmetry, which decayed the APF performance.

\section{Simulation Analysis of APF DC Magnetic Bias}

In order to analyze APF DC magnetic bias model, the simulation system was established to study the influence of DC magnetic bias. Iron core reactor was selected as APF filter reactor. Silicon steel sheet was usually chosen as iron core material of APF device, and its saturated induction intensity was normally between $1.9 \mathrm{~T}$ and $2.0 \mathrm{~T}$. The expression for the $B-H$ function could be fitted according to the magnetization curve. Consider the following:

$$
B=\alpha_{1} \arctan \frac{H}{K}+\alpha_{2} H,
$$

where $\alpha_{1}=1.121$ and $\alpha_{2}=5.937 \times 10^{-6}$ were the fitting coefficients. $H$ was magnetic field intensity and $K$ was 204.4 . The fitting curve was shown in Figure 4.

According to the definition of magnetic field intensity,

$$
H=\frac{N_{j}}{l_{j}} i(t),
$$

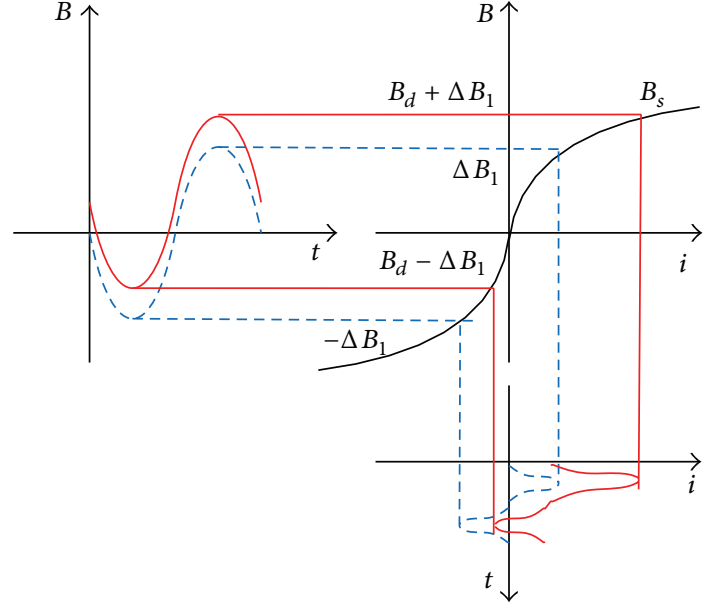

FIgURE 3: Current and flux based on DC magnetic bias of APF.

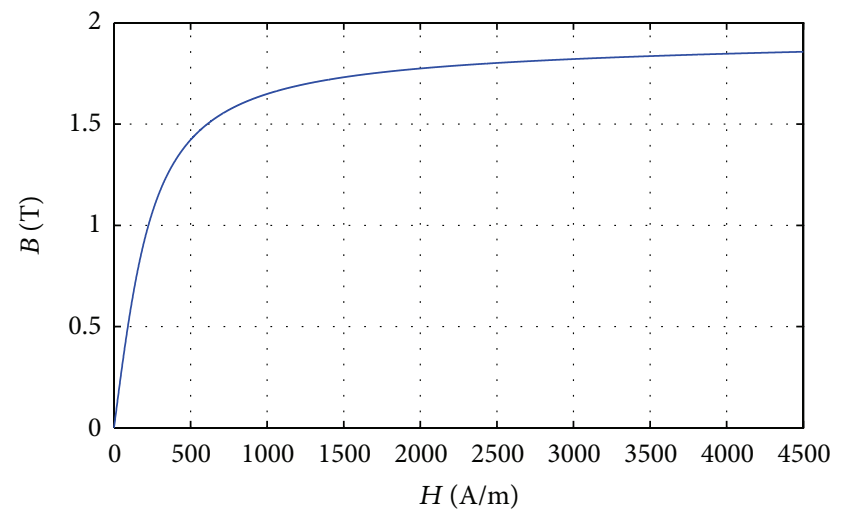

FIgURE 4: Magnetization curve of silicon steel sheet.

where $N_{j}$ and $l_{j}$ were the number of windings and magnetic path length of reactor, and $i(t)$ was output current of APF. Assumed APF mainly suppressed 5th, 7th, and 11th harmonic currents; output current of phase A would be

$$
\begin{aligned}
i(t)= & I_{d}+\sqrt{2} I_{5} \sin \left(5 \omega_{0} t\right)+\sqrt{2} I_{7} \sin \left(7 \omega_{0} t\right) \\
& +\sqrt{2} I_{11} \sin \left(11 \omega_{0} t\right),
\end{aligned}
$$

where $I_{d}$ was DC current and $I_{n}(n=5,7,11)$ was each order harmonic current amplitude. According to (7) and (9), magnetic induction intensity could be expressed as

$$
B=f(t)=\alpha_{1} \arctan \frac{N_{i} i(t)}{K l_{i}}+\alpha_{2} \frac{N_{i}}{l_{i}} i(t) .
$$

According to the law of electromagnetic induction, magnetic induction intensity in the iron core of APF reactor would induce electromotive voltage and produce induced current $i(t)$, and it could be expressed as

$$
i(t)=-\frac{N_{i} S}{r} \cdot \frac{d B}{d t} .
$$



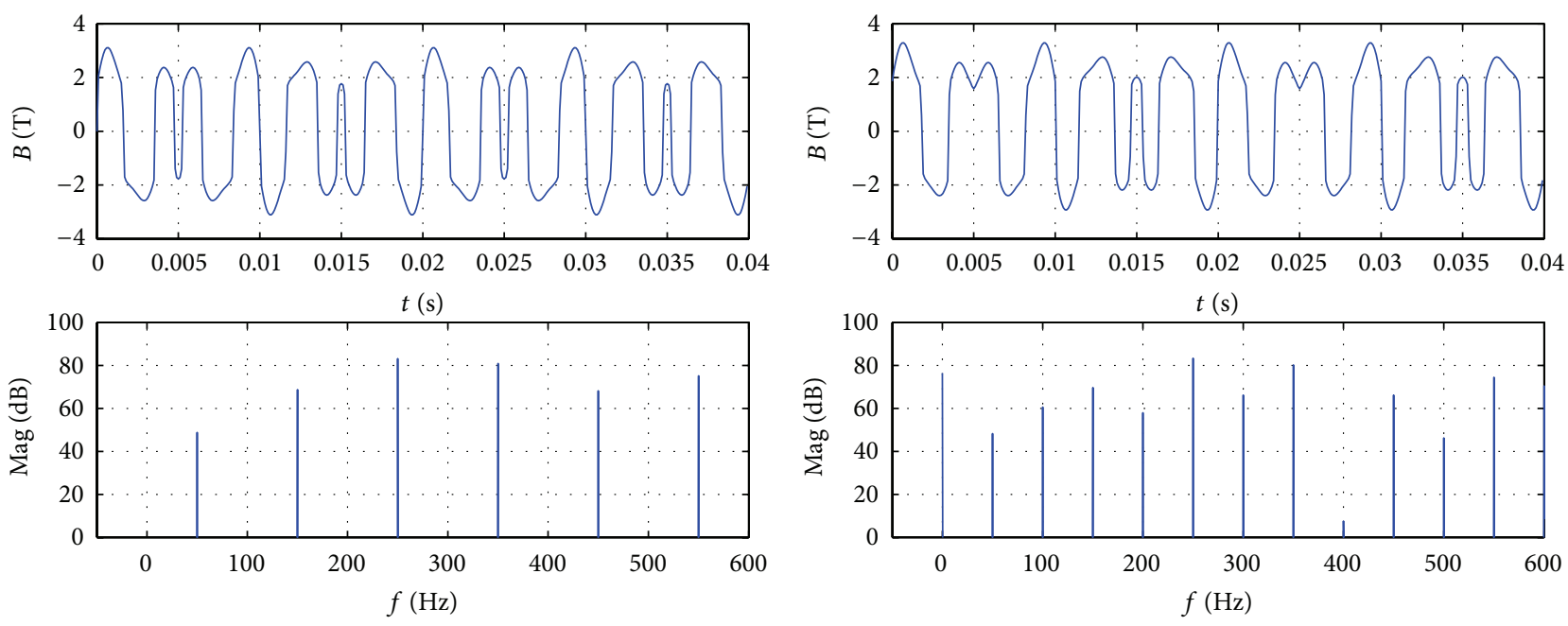

(a) Waveform and frequency spectrum when $I_{d}$ is zero

(b) Waveform and frequency spectrum when $I_{d}$ is $5 \mathrm{~A}$
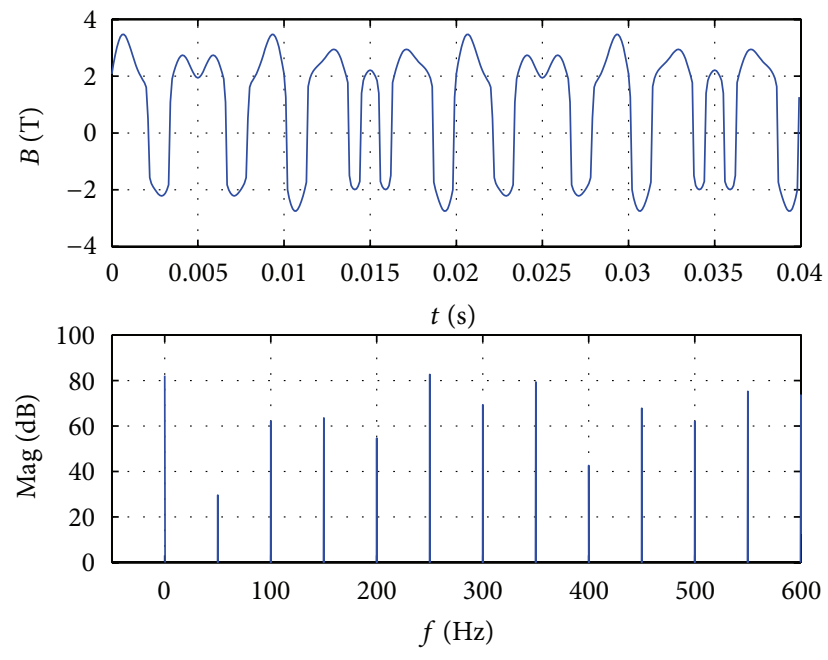

(c) Waveform and frequency spectrum when $I_{d}$ is $10 \mathrm{~A}$

FIgURe 5: Magnetic induction intensity via the different DC magnetic bias.

From (11), harmonic components in induction current were equivalent to harmonic components in magnetic induction intensity. According to Fourier decomposition of (10), frequency spectrogram of magnetic induction could be obtained. Therefore, thing $N_{i}=300$ turn, $l_{i}=0.5 \mathrm{~m}$, $I_{5}=20 \mathrm{~A}, I_{7}=14.29 \mathrm{~A}$, and $I_{11}=9.1 \mathrm{~A}$, the relation between magnetic induction intensity and DC current $\left(I_{d}\right)$ would be analyzed. And the simulation result with different $I_{d}$ was shown in Figure 5 . When $I_{d}=0$, there are only odd harmonics in magnetic induction intensity. If DC current existed, even harmonics in magnetic induction intensity were created. With the DC current increasing, DC magnetic bias became more and more serious and even harmonics of induction intensity increased (second harmonic was the most significant in the even harmonics). And output current of APF was distorted at same time, which worsened the APF performance. So more even harmonics current were injected into the power system and reduced the power quality. From the simulation results with different DC magnetic bias conditions, we could see that the DC magnetic bias would decay the magnetic excitation process, which would reduce the performance of APF.

\section{Improved Method and Experiment of APF}

Iron core reactor of APF would lead DC magnetic bias while running and it could produce more even harmonics current and reduce the performance of APF. Particular attention should be paid to loss and overheat of the reactor when DC magnetic bias was serious. So, improved methods of DC magnetic bias were proposed and the improved methods were listed as follows.

(1) Main circuit parameters of APF devices and reactor characteristics may be uniform and reluctance of iron core was increased to enhance the ability against DC magnetic bias. 


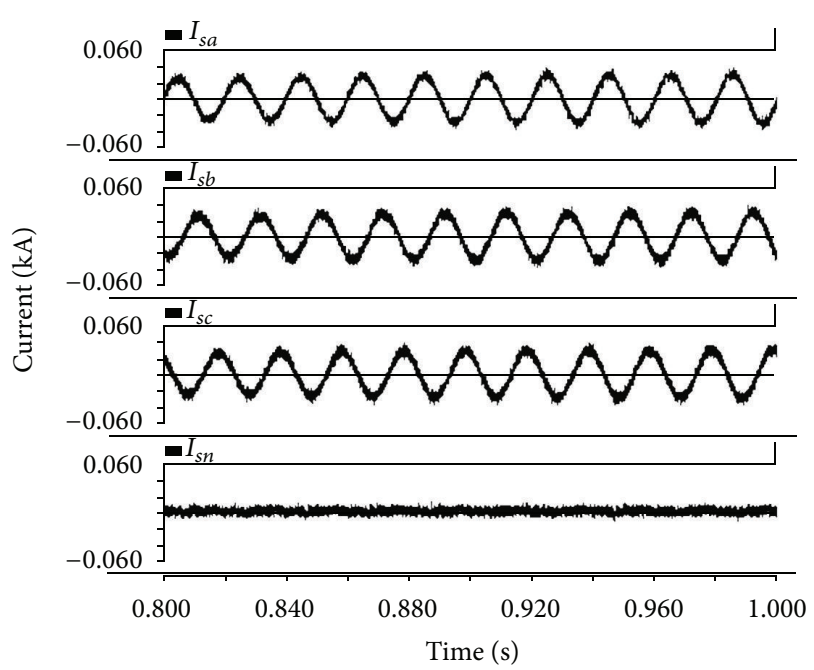

(a) System current of APF running with DC bias

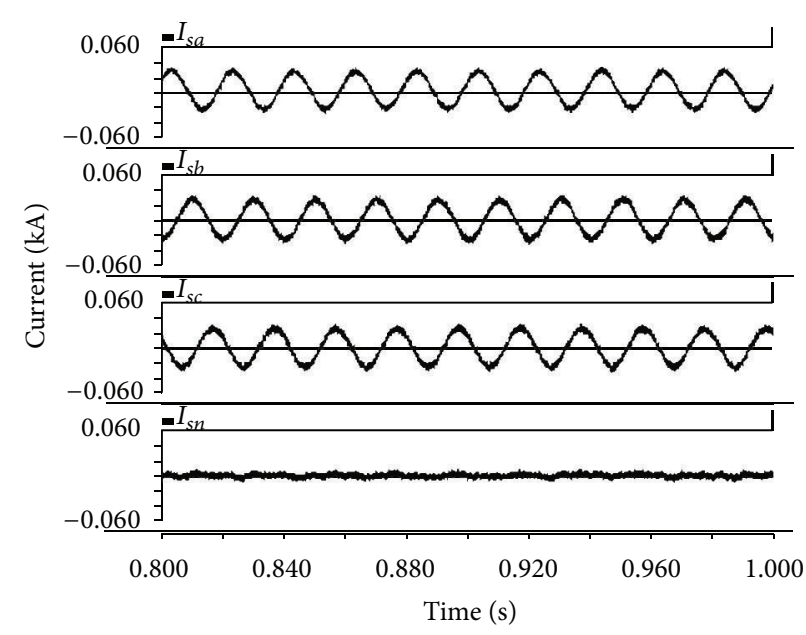

(c) System current of APF running with improved methods

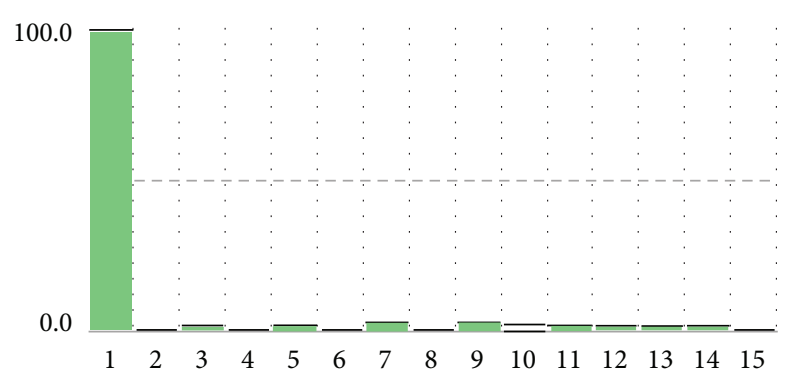

(b) THD simulation of APF running with DC bias

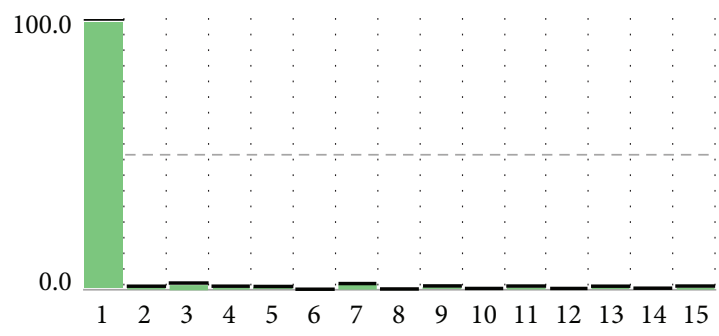

(d) THD simulation of APF running with improved methods

FIgURE 6: Simulation results of APF performance.

(2) Three-phase control parameters must be uniform and maximum variation rate of reference current in APF should be limited to ensure current symmetry in positive and negative half-wave region.

(3) Soft start technology can be used to prevent starting transient saturation and the minimum duty ratio of driving signal should be limited.

The simulation system of APF with DC magnetics bias influence was established in PSCAD environment, which could verify improved methods. In the simulation, AC power frequency was $50 \mathrm{~Hz}$, phase voltage amplitude was $220 \mathrm{~V}$, and the main circuit topology was three-phase four-leg inverter. The nonlinear load was three-phase rectifier, and the load was $10 \Omega$ resistor series-wound to the $5 \mathrm{mH}$ inductance. The DC current signal would be added to the reference current of APF to simulate DC magnetics bias, and simulation results were shown in Figure 6. System current of APF running with DC bias was shown in Figure 6(a), system current of APF running with improved methods was shown in Figure 6(b), and the system current total harmonic distortion (THD) simulation result of APF by improved methods was given in Figure 6(c). In Figure 6, $I_{s a}, I_{s b}$, and $I_{s c}$ were system phase current after APF running, and $I_{s n}$ was the zero-line current of system side. From Figure 6, it could be seen that, because of DC magnetic bias of APF, the operation performance was affected, and the system current contained the even harmonic components. The improved method could reduce DC magnetic bias, and even harmonic components of system current were reduced, which improved the APF operation performance. The system current with DC bias deviated from the coordinate origin and was asymmetric, which brought more even harmonic components, see Figures 6(a) and 6(b). However, the system current was symmetrical after processing by the proposed methods, which compressed even harmonic currents, see Figures 6(c) and 6(d). So, the proposed method could restrain DC magnetic bias to improve the APF performance. 


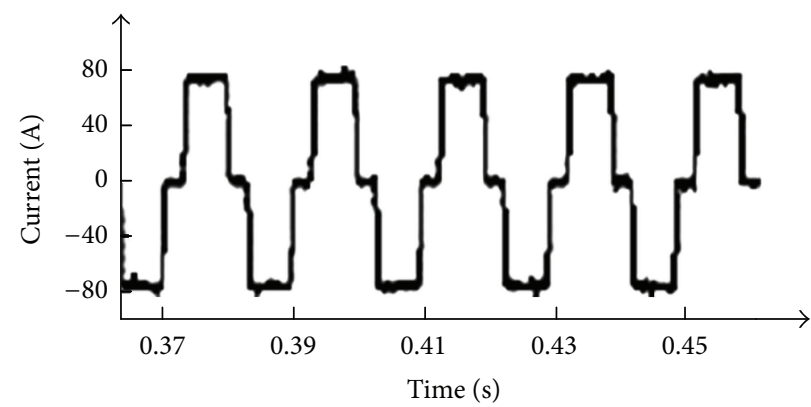

(a) Load current wave

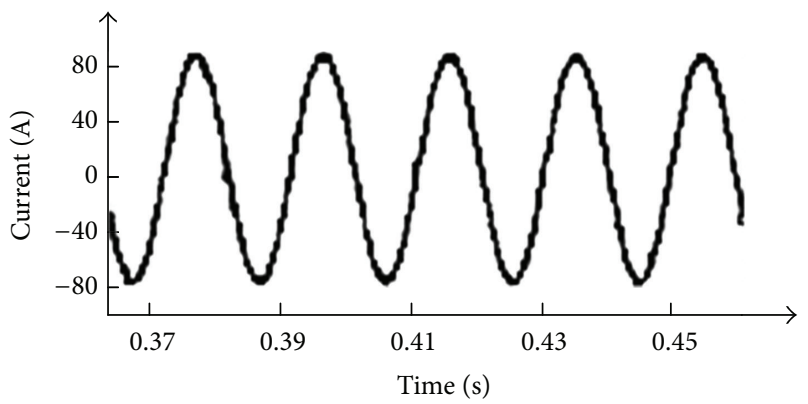

(c) System current of APF running with improved method

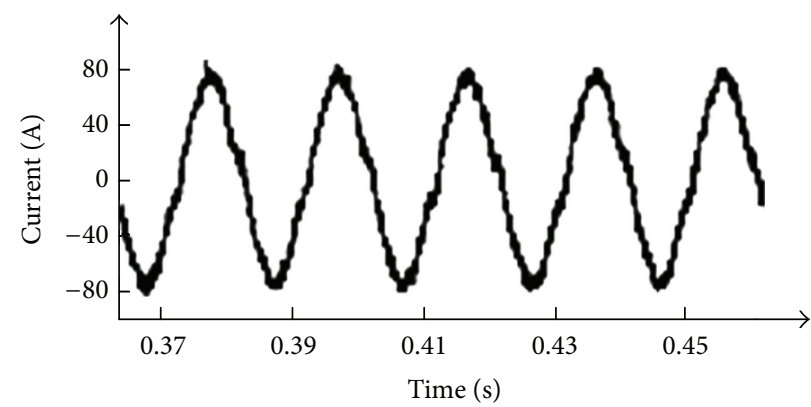

(b) System current of APF running with DC bias

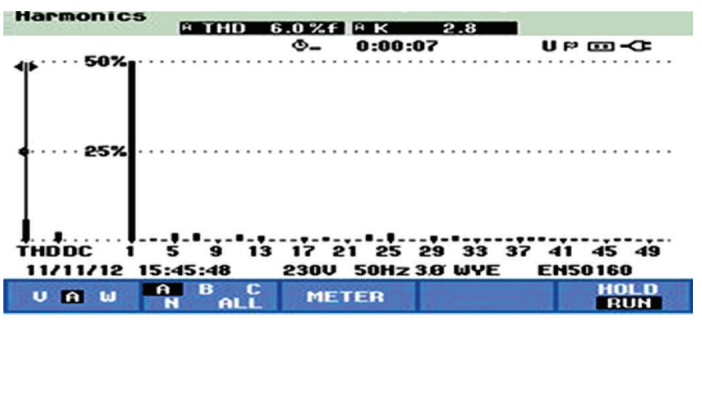

(d) THD simulation of APF running with improved method

FIGURE 7: Simulation result of APF performance.

In order to verify DC magnetics bias influence and improved methods, experiment platform was established. Iron core inductors, intelligent power module (PM75RSE120), and capacitors are used to design main circuit of the three-phase four-wire APF device. AC power frequency was $50 \mathrm{~Hz}$ and voltage amplitude was $220 \mathrm{~V}$. The iron core reactor was selected as the filter reactor of APF and the inductance was $4 \mathrm{mH}$. To produce harmonic current, the nonlinear load was three-phase rectifier, and the load was $8 \Omega$ resistor serieswound to the $5 \mathrm{mH}$ inductance. When APF was running, the DC current would be added to the reference current of APF to simulate DC magnetics bias of iron reactor. The experimental results were shown in Figure 7. The waveform in Figure 7(a) was the nonlinear load current of the phase A, the waveform in Figure 7(b) was the system current of phase A after compensation of APF with DC magnetic bias, and the waveform in Figure 7(c) was system current of phase A after compensation of APF with DC magnetic bias improved method. In order to validate the performance of the proposed method, total harmonic distortion (THD) analysis was shown in Figure 7(d).

From Figure 7, because of the nonlinear load, the load current was distorted. It contained many harmonic components. With reactor DC magnetic bias of APF, output current contained the even harmonic components, the filtering performance was affected, and distortion rate of power system side current after filtering by APF was $13.54 \%$. With DC magnetic bias optimization method, even harmonic current in APF device output current was reduced. The distortion rate of power system side current after filtering by APF was
TABLE 1: Harmonic analysis of system side current.

\begin{tabular}{lcc}
\hline Harmonic order & Nonoptimization & Optimization \\
\hline 2 & 4.78 & 0.55 \\
3 & 1.16 & 0.36 \\
4 & 1.57 & 0.30 \\
5 & 0.56 & 0.52 \\
6 & 1.28 & 0.22 \\
7 & 0.08 & 0.06 \\
8 & 0.78 & 0.17 \\
9 & 1.18 & 0.09 \\
10 & 1.37 & 0.18 \\
11 & 0.95 & 0.63 \\
12 & 1.26 & 0.04 \\
13 & 0.27 & 0.23 \\
\hline THD & $13.54 \%$ & $5.4 \%$ \\
\hline
\end{tabular}

only 5.4\%. So, filtering performance of APF was improved obviously.

In order to analyse the proposed method of DC magnetic bias of APF, the harmonic analytical data of two operational conditions was shown in Table 1 . From Table 1, it can be seen that while APF was working, DC magnetic bias would generate even harmonic current components, such as second and fourth harmonic. The even harmonic current amplitude was large and it would cause power system side current to be distorted, which affected the performance of APF. 
Optimization method must be used to suppress the reactor DC bias to improve APF performance.

\section{Conclusion}

As one of the main power devices of APF, iron core reactor would cause DC magnetic bias at running time, which would cause loss of reactor increasing, output current containing even harmonic currents. APF device performance was decayed. The mechanism of DC bias and mathematical model were analysed in this paper. From the three-phase fourleg APF simulation, it was shown that DC magnetic bias caused by iron core reactor would produce even harmonics injected into the power grid and reduce the performance of APF. The improved method was proposed, and experimental platform was established. Experimental results shown that the improved method can reduce reactor DC magnetic bias and even harmonic current and greatly optimize APF performance. The study of this issue is quite significant for APF application.

\section{Acknowledgments}

This research has been supported by the National Natural Science Foundation of China (no. 61201410) and the Natural Science Fund for Colleges and Universities in Jiangsu Province (11KJB470002). The authors are grateful to the reviewers for their valuable comments.

\section{References}

[1] Z. Wang, J. Yang, and J. Liu, Harmonics Suppression and Reactive Power Compensation, China Machine Press, Beijing, China, 1998.

[2] P. Mattavelli and F. P. Marafao, "Repetitive-based control for selective harmonic compensation in active power filters," IEEE Transactions on Industrial Electronics, vol. 51, no. 5, pp. 10181024, 2004.

[3] Z. Ding, B. Liu, and Y. Zhang, "Optimal control for DC side voltage of active power filter based on auto-disturbance rejection control," Power System Technology, vol. 37, no. 7, pp. 2030-2034, 2013.

[4] J. Le and K. Liu, "Parameters optimization method of threephase four-wire shunt active power filter based on unified mathematical model," Transactions of China Electrotechnical Society, vol. 27, no. 10, pp. 220-227, 2012.

[5] X. Wei, K. Dai, B. Xie, Y. Kang, and H.-L. Peng, "Control scheme for three-phase three-wire shunt active power filter with unbalanced loads," Proceedings of the Chinese Society of Electrical Engineering, vol. 28, no. 24, pp. 64-69, 2008.

[6] H. Pan, A. Luo, and C. Tu, "Development of a shunt type of high power quality regulating device," Power System Technology, vol. 33, no. 1, pp. 11-16, 2009.

[7] M. Izhar, C. M. Hadzer, M. Syafrudin, S. Taib, and I. Idris, "Performance for passive and active power filter in reducing harmonics in the distribution system," in Proceedings of the National Power and Energy Conference (PECon '04), pp. 104108, Kuala Lumpur, Malaysia, November 2004.

[8] G. Y. Jeong, T. J. Park, and B. H. Kwon, "Line-voltage-sensorless active power filter for reactive power compensation," IEE
Proceedings of Electric Power Applications, vol. 147, no. 5, pp. 385-390, 2000.

[9] M. Marius, P. Florin, and S. B. Liliana, "Modeling and simuling power active filter using method of generalized reactive power theory," in Proceedings of the IEEE International Conference on Computer Science and Automation Engineering (CSAE '11), vol. 2, pp. 213-218, Shanghai, China, June 2011.

[10] G. Zhang, C. Zhao, M. Ding, J.-H. Su, and H.-N. Wang, "Simulation analysis of output filter in PAPF system," Journal of System Simulation, vol. 21, no. 4, pp. 969-972, 2009.

[11] G. Zhang, G. Qi, J. Su, M. Ding, L. Chen, and X.-A. Zhang, "A new method of output inductance selection in shunt active power filter," The Chinese Society of Electrical Engineering Proceedings, vol. 30, no. 6, pp. 22-27, 2010.

[12] A. V. Makarov, O. V. Talamanov, and M. E. Kuznethova, "The mathematical model of flexible transmission systems on the magnetic bias controlled reactors basis," in Proceedings of the IEEE Russia Power Tech, St. Petersburg, Russia, June 2005.

[13] R. P. Price, "Geomagnetically induced current effects on transformers," IEEE Transactions on Power Delivery, vol. 17, no. 4, pp. 1002-1008, 2002.

[14] K. Dizheng, L. Chengmin, and D. Wan, "Experiment and research of the influence of direct-current magnetic bias on transformer," Electric Power, vol. 37, no. 8, pp. 12-13, 2004.

[15] A. Dovzhenko, Y. Yanovskaya, V. Pilinsky, and V. Shvaichenko, "Research of influencing of DC magnetic bias process of core of inductive slements of converters on the radiofrequency interferences of equipments," in Proceedings of the International Conference on Modern Problems of Radio Engineering and Telecommunications and Computer Science, vol. 1, p. 231, LvivSlavsko, Ukraine, February 2008.

[16] Z. Linsuo, Z. Zhanxin, B. Baodong, and Y. Song, "Research on influence of DC magnetic bias on a converter transformer," in Proceedings of the International Conference on Electrical Machines and Systems (ICEMS '07), vol. 1, pp. 1346-1349, Seoul, Republic of Korea, October 2007.

[17] S. Yin, S. Ding, A. Haghani, H. Hao, and P. A. Zhang, "Comparison study of basic data-driven fault diagnosis and process monitoring methods on the benchmark Tennessee Eastman process," Journal of Process Control, vol. 22, no. 9, pp. 1567-1581, 2012.

[18] S. Yin, S. Ding, and H. Luo, "Real-time implementation of faulttolerant control system with performance optimization," IEEE Transactions on Industrial Electronics, vol. 61, no. 5, pp. 24022411, 2013.

[19] S. Yin, S. Ding, A. Haghani, and H. Hao, "Data-driven monitoring for stochastic systems and its application on batch process," International Journal of Systems Science, vol. 44, no. 7, pp. 13661376, 2013.

[20] S. Yin, X. Yang, and H. Karimi, "Data-driven adaptive observer for fault diagnosis," Mathematical Problems in Engineering, vol. 2012, Article ID 832836, 21 pages, 2012. 


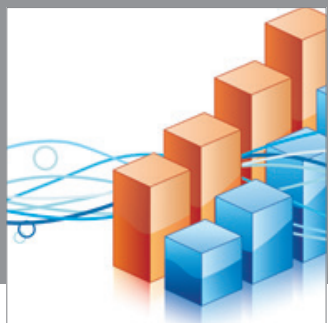

Advances in

Operations Research

mansans

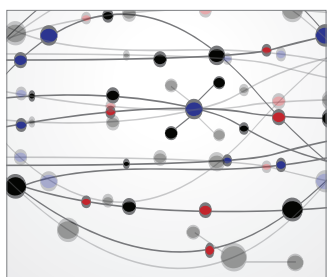

The Scientific World Journal
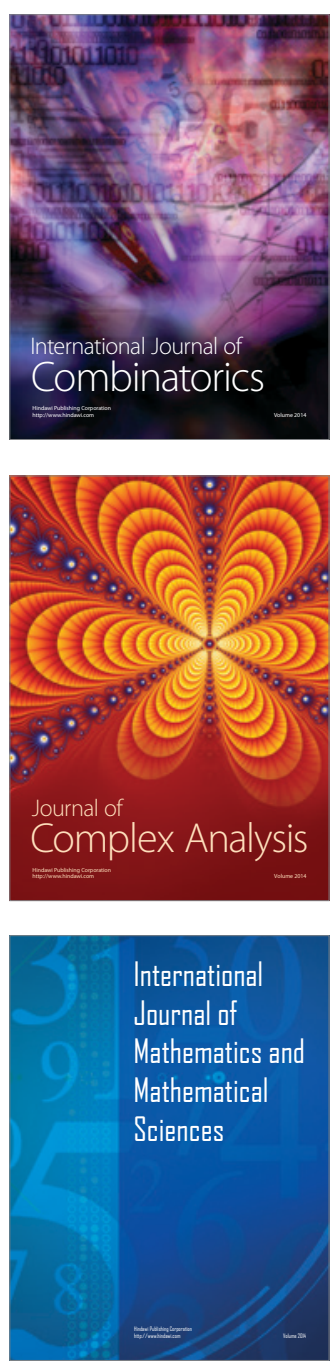
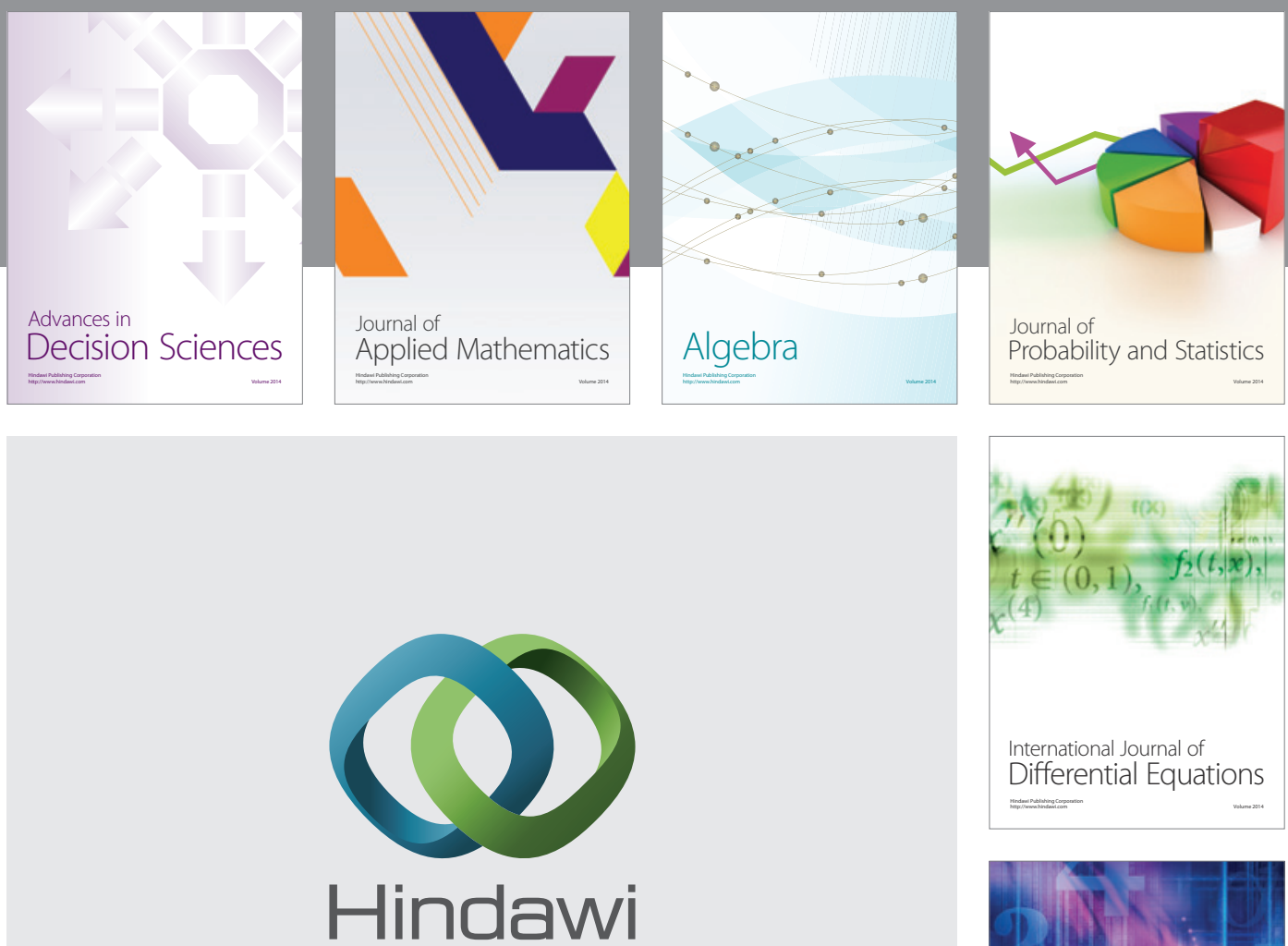

Submit your manuscripts at http://www.hindawi.com
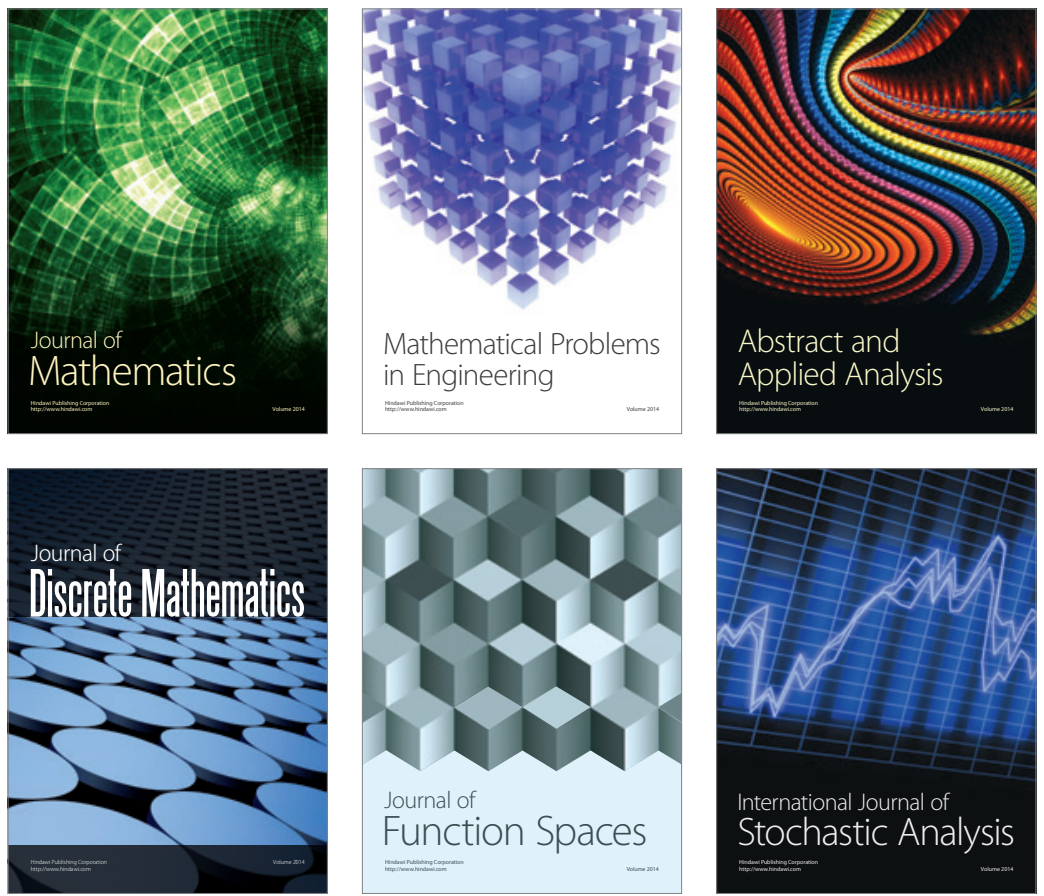

Journal of

Function Spaces

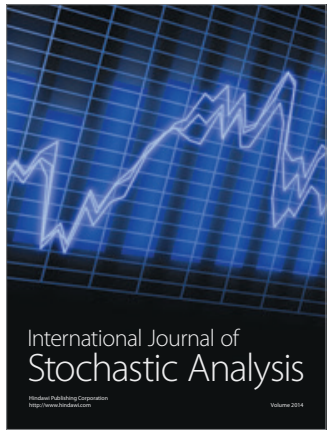

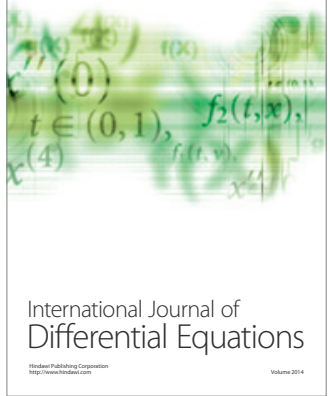
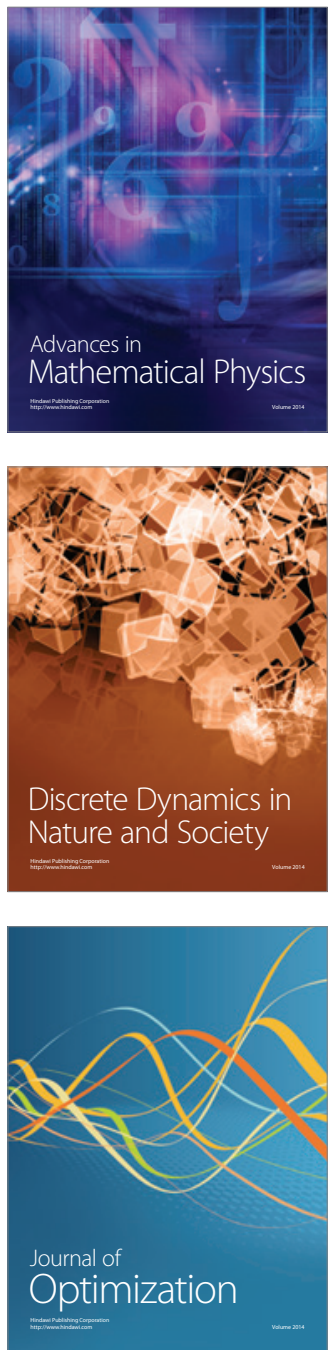